\title{
Análise linguística integrada à leitura: contribuições para a prática docente em língua portuguesa
}

\author{
Liliane Vanilde de Souza ${ }^{1}$ \\ Instituto Federal de Educação Ciência e Tecnologia de Santa Catarina, Florianópolis, SC, Brasil \\ Natassia D’Agostin Alano² \\ Universidade Federal de Santa Catarina, Florianópolis, SC, Brasil
}

Sabatha Catoia Dias ${ }^{3}$

Universidade Federal de Rio Grande, Rio Grande, RS, Brasil

\begin{abstract}
Resumo: Este artigo tem como objetivo discutir a importância da análise linguística integrada ao ensino e à aprendizagem de leitura nas aulas de Língua Portuguesa no contexto de escolas de Educação Básica. As bases teórico-epistemológicas e metodológicas que sustentam este artigo são a perspectiva bakhtiniana em diálogo com estudos sociocognitivistas. A discussão decorre de uma preocupação com o tradicional trabalho de análise gramatical ainda presente em aulas de Língua Portuguesa, pautado em leituras descontextualizadas de textos, na maioria das vezes, fragmentados. Nosso propósito, desse modo, é contribuir, em alguma medida, com a prática docente no que diz respeito à análise da língua em articulação com a leitura de textos em gêneros do discurso diversos, de modo a delinear possibilidades ao trabalho escolar.
\end{abstract}

Palavras-chave: Análise linguística; Leitura; Ensino e Aprendizagem de Língua Portuguesa.

Title: Linguistic analysis integrated to reading: contributions to the teaching practice in Portuguese Language

Abstract: This article aims to discuss the importance of integrated linguistic analysis to teaching and reading learning in Portuguese Language classes in the context of Basic Education schools. The theorical-epistemological and methodological basis that supports this article is the Bakhtinian perspective in dialogue with socio-cognitive studies. The discussion stems from a concern with the traditional work of grammatical analysis still present in Portuguese Language classes, based on decontextualized reading of texts, mostly fragmented texts. Our purpose, in this way, is to contribute, in some way, to the teaching practice concerning the

\footnotetext{
${ }^{1}$ Mestra em Linguística no Programa de Pós-graduação em Linguística da Universidade Federal de Santa Catarina (UFSC). Técnica em Assuntos Educacionais do Instituto Federal de Educação Ciência e Tecnologia de Santa Catarina (IFSC). Orcid: https://orcid.org/0000-0002-3337-2754

E-mail: liliane.souza@ifsc.edu.br

${ }^{2}$ Doutoranda em Linguística no Programa de Pós-graduação em Linguística da Universidade Federal de Santa Catarina (UFSC). Orcid: https://orcid.org/0000-0001-7932-0100

E-mail: tassidagostin@gmail.com

3 Docente do Curso de Letras na Universidade Federal de Rio Grande (FURG). Orcid: https://orcid.org/0000-0002-2446-303X

E-mail: sabathacatoia@furg.br
} 
analysis of the language in articulation with the reading of texts in different discourse genres, in order to delineate possibilities to the school work.

Keywords: Linguistic analysis; Reading; Teaching and Learning of Portuguese Language.

\section{Introdução}

A leitura, compreendida como um complexo processo cultural (GEE, 2004) que envolve a interação entre autor e leitor por meio de textos-enunciados ${ }^{4}$ para a produção de sentidos (ANTUNES, 2010; KOCH; ELIAS, 2012) - uma vez que o ato de ler tem implicações intersubjetivas, visto que se realiza na interação real entre seus interlocutores por meio da língua(gem) ${ }^{5}$, de modo que nessas vivências interativas de leituras os sujeitos vão também se constituindo (BAKHTIN, 2010 [1920-1924]; 2011 [1979]) -, adquire importância capital nos processos de escolarização, levando-se em conta, ainda, a demanda pela cultura escrita de uma sociedade cada vez mais grafocêntrica (FISCHER, 2006).

Em se tratando do ensino e da aprendizagem da leitura nas escolas de Educação Básica, por muito tempo o trabalho escolar esteve pautado na imanência da língua, estando os textos inseridos em sala de aula apenas para a realização de atividades gramaticais, ou como objeto de imitação ou de fixação de sentidos (GERALDI, 1997). Entretanto, com a publicação dos Parâmetros Curriculares Nacionais na década de 1990, impulsionados também por estudos e publicações de ordem sociologista na área da educação em linguagem, a exemplo de Geraldi $(1984,1997)$ e Britto (1997), o trabalho com o texto em sala de aula parece ter adquirido um novo enfoque, ao menos sob a ótica científico-acadêmica. Passou-se a considerar, então, os usos sociais da linguagem, e não mais apenas o sistema linguístico em si. No âmbito escolar, no entanto, apesar do suporte teórico-epistemológico evidenciado, sobretudo, nos documentos parametrizadores da educação, parece ainda não ter havido uma apropriação dessas concepções a que vimos, aqui, nos referindo - tal qual sugerem estudos na área - e, por via de consequência, um trabalho com leitura e com análise linguística à luz dessas mesmas compreensões.

Assim, buscamos tematizar, neste artigo, a análise linguística integrada à leitura, com o intuito de contribuir para a prática docente de professores de Língua Portuguesa, propondo

\footnotetext{
${ }^{4}$ Valemo-nos desta expressão por entendermos que 'texto', nos escritos do Círculo, compartilha das mesmas feições constitutivas do 'enunciado'.

${ }^{5}$ No que concerne à concepção de língua/linguagem, importa ressaltar nossa compreensão de que a dicotomização entre língua e linguagem não nos é necessária porque compreendemos ambas na perspectiva da interação situada entre o eu e o outro. Ainda que linguagem possa ser entendida em um sentido mais amplo, como em linguagem das artes, por exemplo, entendemos que a perspectiva interacional mantém-se como fundante nessa relação. Desse modo, vemo-nos liberadas, de agora em diante, neste artigo, de optar por uma ou outra forma sem agenciar compreensões diferentes para cada uso.
} 
uma discussão de cunho teórico-metodológico em torno dessa questão. Para isso, valemo-nos do amplo espectro do Círculo de Bakhtin - ideário aqui nomeado como sociointeracionista/enunciativo-discursivo -, bem como das contribuições da Linguística Textual (ANTUNES, 2003, 2009, 2010; KOCH, 1999, 2002, 2004, 2014; KOCH; ELIAS, 2012; MARCUSCHI, 2008), ideário aqui referido como sociocognitivista/cognitivista. Além disso, para ampliar as discussões acerca do trabalho com leitura e análise linguística na escola, faremos menções às teorizações de Geraldi (1984, 1997, 2010) e Britto (2003, 2012), por entendermos que esses autores dialogam com os postulados bakhtinianos e trazem contribuições significativas no que diz respeito ao trabalho com o texto em sala de aula.

Tendo em vista essas considerações, este artigo, sustentado pelas bases sociointeracionista e sociocognitivista, é organizado em três eixos, quais sejam: i) leitura à luz das bases teórico-epistemológicas, em que abordamos a concepção de leitura com que vimos trabalhando, assim como as implicações a partir de tal concepção; ii) análise linguística à luz das bases teórico-epistemológicas, abarcando a distinção entre gramática tradicional e análise linguística e de que modo pode ser concebido o trabalho de análise da língua na sala de aula com base nos pressupostos do Círculo e da Linguística Textual; iii) contribuições para a prática docente em Língua Portuguesa, no qual nos propomos a pensar possíveis 'caminhos' para o trabalho com a análise linguística integrada à leitura em sala de aula, em escolas de Educação Básica.

Destacamos, ainda, que este texto não consiste em um modelo prescritivo a ser seguido, mas constitui uma tentativa de pensar em possibilidades outras para o estudo da linguagem na escola por meio da leitura, na busca por contribuir, de algum modo, para um efetivo e teoricamente amparado trabalho docente (RODRIGUES; CERUTTI-RIZZATTI, 2011) em Língua Portuguesa.

\section{Leitura à luz das bases teórico-epistemológicas}

Ainda que a modalidade oral, entre os falantes, prevaleça em nossa sociedade, a escrita nunca esteve tão presente como no século atual. Encontramos essa modalidade da língua em diferentes espaços e suportes; não é exagero considerar que ela compõe a cidade e, portanto, também a nossa vida. Assim, interagir no ambiente social, hoje, é estar diante de um mundo permeado pela cultura escrita (BRITTO, 2003, 2005; CERUTTI-RIZZATTI, 2011), o que exige de nós atenção cada vez maior a essa especificidade.

Embora a escrita esteja em foco e nossas ações sejam permeadas por ela, parece ainda persistir, em diferentes ambientes, o discurso de que nossa sociedade é formada por não leitores (BRITTO, 2003, 2012). Nesses casos, a nosso ver, o ato de considerar os alunos como 
(não) leitores consiste em uma questão mais ampla que transcende leituras de gêneros secundários (BAKHTIN, 2011 [1952-1953]), aquelas as quais denominamos leituras literárias, filosóficas, científicas, etc., historicamente assumidas como leituras efetivas. Hoje, pautados nos estudos bakhtinianos acerca de gêneros do discurso, assumimos que a leitura extrapola o mundo da erudição, integrando o cotidiano da vida social no que tange à circulação de textos em gêneros primários, sem, contudo, restringir-se a eles, ou seja, a leitura institui relações interpessoais por meio de textos pertencentes a diferentes gêneros do discurso que circulam em distintas esferas da atividade humana, em situações públicas e privadas. Assim, se os nossos alunos estão sendo considerados 'não leitores', isso parece se dar por conta de compreensões pouco elaboradas do que seja "ler" e ainda distantes de questões culturais, sociais e econômicas envolvidas. Entretanto, tais compreensões nos chamam, enquanto especialistas, a refletir acerca do papel do professor de Língua Portuguesa no que tange ao uso do texto em sala de aula, mais especificamente do que consideramos leitura à luz das bases teórico-epistemológicas que compõem este artigo.

João Wanderley Geraldi, no início da década de noventa, em seu livro seminal, Portos de Passagem, já sinalizava para um "novo" olhar acerca do trabalho com os textos em sala de aula. O autor, ao discutir o propósito do ensino de Língua Portuguesa nas escolas de Educação Básica, faz uma crítica argumentando que, embora o trabalho com linguagem venha se caracterizando pela presença do texto no processo de produção escrita e de leitura, o texto tende a ser utilizado nas aulas de Língua Portuguesa de um modo estanque, fixando, portanto, a dinamicidade e tornando-se um produto pronto e acabado.

Com o advento das obras do Círculo de Bakhtin, no ocidente, a crítica de Geraldi (1997) parece acompanhar a guinada dos estudos sociologistas. Soma-se a isso, a publicação dos Parâmetros Curriculares Nacionais (1998) que é resultado das discussões mais amplas de um olhar que concebe o ensino e a aprendizagem de Língua Portuguesa tendo por base os gêneros do discurso (BAKHTIN, 2011 [1952-1953]).

Ao considerarmos essas questões que envolvem o trabalho com o texto em sala de aula, tendo como eixo a leitura, podemos acrescentar que essa discussão é foco em diferentes áreas correspondentes aos estudos da língua. No entanto, como já salientado, nosso olhar parte de um diálogo entre a linha sociointeracionista e a linha sociocognitivista. Partimos dessas duas perspectivas por entendermos que pensar a ação escolar - o que implica pensarmos em um espaço institucionalizado, em sujeitos singulares, e em práticas de uso da língua específicas exige que tenhamos uma concepção que englobe esses dois polos, uma vez que ler implica operações cognitivas que só se justificam em razão de a leitura ser uma prática social pela qual se estabelece a produção de sentidos e a apropriação de saberes. Assim, buscamos não dissociar a cognição e a interação, mas conceber o ato de ler à luz da interação entre autor e leitor por meio do texto escrito, situado na história e na cultura. Para isso, é imprescindível que 
tracemos um olhar acerca das duas linhas teóricas mencionadas anteriormente, a fim de acentuarmos a importância dessa não dissociação em se tratando do trabalho com a leitura na sala de aula. Nesse sentido, abordaremos, inicialmente, o trabalho com o ato de ler na perspectiva sociointeracionista para, em seguida, tratá-lo do ponto de vista da perspectiva sociocognitivista.

No que concerne à formação leitora na escola, a perspectiva sociointeracionista à luz do Círculo de Bakhtin nos é cara, pois entendemos que formar leitores tem implicações de natureza social, cultural e histórica. Concebendo a leitura como um complexo processo cultural que envolve a interação entre autor e leitor por meio de textos-enunciados para a produção de sentidos (GEE, 2004), entendemos que o ato de ler extrapola atividades de decodificação e localização de informações, resultando em um trabalho mais amplo e de relações que ultrapassam o contato com o texto materializado, o que torna o trabalho do professor mais abrangente no que diz respeito à atenção a aspectos textuais ou aspectos imanentes da língua.

Conceber a leitura como um processo cultural - relacionado às vivências dos sujeitos com a língua, as suas experiências como leitores - significa que quanto mais inseridos, familiarizados e habituados nossos alunos estiverem com diferentes gêneros do discurso, mais ampliadas serão suas práticas de uso da língua, o que contribui para sua formação como leitores de textos nos mais variados gêneros do discurso, em diferentes espaços sociais, e mais próximos de se tornarem, portanto, possíveis leitores proficientes.

Segundo Medviédev (2012 [1928], p. 201), "Os gêneros do discurso não se encontram deslocados das atividades humanas; o gênero lança uma luz sobre a realidade, enquanto a realidade ilumina o gênero". Falamos por meio de gêneros, escrevemos e lemos textosenunciados que estão dentro de um determinado gênero. Nosso discurso está situado dentro de um contexto específico. Conforme Volochínov (2013 [1930], p. 127), “a palavra é uma ponte lançada entre mim e os outros. Se uma extremidade desta ponte se apoia sobre mim, a outra se apoia sobre meu interlocutor. A palavra é o território comum existente entre o falante e o interlocutor", assim, o leitor, sujeito ativo, delineia os sentidos no encontro com a palavra outra e com base nas vivências empreendidas nos grupos sociais de que toma parte.

Com base em Cerutti-Rizzatti, Daga e Catoia Dias (2014, p. 228), seria nosso desiderato, como professores de Língua Portuguesa, organizar uma ação pedagógica considerando a leitura nas diferentes relações sociais. Esse encaminhamento requer tomar textos em diferentes gêneros do discurso, tanto primários quanto secundários, que instituem relações interpessoais nas mais variadas esferas da atividade humana, sejam elas públicas ou privadas, a fim de que nossos alunos aprendam e se desenvolvam no tocante aos diferentes usos da língua, bem como ao alargamento de suas representações de mundo. 
À luz das bases-epistemológicas, concebendo, portanto, a língua como instituidora das relações humanas e o sujeito como constituído na relação com o outro, trabalhar com leitura no plano sociologista exige-nos, como professores de Língua Portuguesa, que compreendamos a historicidade e a constituição de nossos alunos como leitores, a fim de buscar incidir e ampliar suas práticas de leitura. Esse modo de trabalhar com a leitura em sala de aula nos parece um caminho possível, de modo que não devemos nos restringir às leituras estanques alvo de crítica de Geraldi (1997) - a leitura vozeada, a leitura como objeto de imitação ou como objeto de fixação de sentidos -, mas, em vez disso, ver a leitura como o 'lugar em que o encontro se dá'.

A perspectiva sociocognitivista, mais especificamente os estudos no campo da Linguística Textual (ANTUNES, 2003, 2009, 2010; KOCH, 1999, 2002, 2004, 2014; KOCH, ELIAS, 2012; MARCUSCHI, 2008), no que diz respeito aos propósitos deste artigo, apesar de não se aprofundar em estudos que contemplem as relações interpessoais - que envolvem os sujeitos em sua corporeidade e historicidade, bem como a esfera da atividade humana de maneira mais ampla - ainda assim, tem sua importância no trabalho com a leitura, haja vista o enfoque na materialidade do texto, isto é, em como o projeto de dizer do autor se constrói textualmente.

Se, tal como expõe Geraldi (1997), o leitor trabalha para reconstruir o dito baseado no que se disse, exige-se do leitor não apenas o que está no plano das relações interpessoais. $O$ encontro entre autor e leitor é concebido na medida em que o sujeito que lê ativa uma série de conhecimentos como, por exemplo, os conhecimentos linguísticos, enciclopédicos e interacionais, realizando inferências e referenciações, compreendendo intertextualidades, e lançando mão de tantas outras estratégias sociointeracionais e cognitivas ( $\mathrm{KOCH}, 2014)$.

$\mathrm{Na}$ ação docente, em se tratando da leitura, é importante que nós, professores de Língua Portuguesa, eduquemos nossos alunos a fim de que percebam essas especificidades do texto os recursos lexicais e gramaticais agenciados pelo autor em seu projeto de dizer - bem como as particularidades de cada gênero do discurso trabalhado, tanto no que diz respeito ao conteúdo temático quanto ao estilo e à construção composicional (BAKHTIN, 2011 [1952-1953]).

\section{Análise linguística à luz das bases: gramática tradicional versus análise linguística}

É frequente no ensino e na aprendizagem de Língua Portuguesa nas escolas básicas o uso de frases soltas, a fim de um objetivo maior: ensinar gramática. Apesar de um crescente estudo teórico-metodológico de cientistas em grandes centros universitários, entre a década de 80 até os dias atuais, tematizando a ineficiência ao se prezar, nas aulas de Português, pelo foco na imanência da língua e não no texto, é perceptível - tanto à luz dos materiais didáticos 
universalizantes quanto na prática docente ${ }^{6}$ - que o ensino da língua portuguesa centra-se, ainda, na gramática tradicional.

Se, por um lado, parece-nos que a teoria se encaminha por uma via cuja discussão é pautada em torno da língua como uma atividade cultural, histórica e social; por outro, as práticas em nossas escolas parecem, muitas vezes, permanecer em propostas obsoletas de ensino, prezando pela análise gramatical de determinado excerto textual, ou, em muitos casos, ao prezar pelo uso do texto em sala de aula, propõem-se atividades de interpretação de texto que, segundo Antunes (2010, p. 21), “incidem em opiniões pessoais acerca de aspectos temáticos abordados ou que [...] dispensam a consulta ao que foi lido. Por esses prismas, [...] não são [...] atividades de análise de texto".

Nesse sentido, por mais que pesquisas advoguem em favor de uma prática docente em língua portuguesa que conceba a língua, em suas modalidades oral e escrita, como atividade social presente em diferentes esferas da atividade humana, é comum generalizações precipitadas - que partem dos professores, dos pais e da mídia - de que na escola os alunos precisam, sobretudo, ter aulas de gramática.

As considerações enviesadas de que os estudos linguísticos de cunho enunciativodiscursivo não visam a um ensino de gramática é um dos argumentos inconsistentes que muito se tem empregado a fim de desmerecer o trabalho com o texto em sala de aula. Tomar a língua nas situações de interação não significa desconsiderar aspectos linguísticos do texto ou não assumir uma reflexão pautada em operações com a linguagem, sobre a linguagem e da linguagem. Contrariamente, segundo Geraldi (1997, p. 54, grifos nossos), “a [...] linguagem, enquanto sistematização aberta, histórica e socialmente produzida, impõe, por seu turno, ela própria, uma realidade, restrições aos tipos de ações que com ela podemos fazer ou que sobre ela podemos fazer." Assim, conceber a língua tal qual vimos concebendo aqui, não significa lidar com os gêneros do discurso no propósito de realizar análise gramatical conforme compreendida tradicionalmente, mas, com a intenção de ampliar as práticas de uso da língua dos sujeitos, tomando a análise linguística em favor do ato de dizer desses mesmos sujeitos, como leitores e produtores de textos em suas variadas formas de realização.

A análise linguística a qual buscamos nos referir neste artigo se pauta, portanto, nas teorizações da perspectiva enunciativo-discursiva e sociocognitivista, visando a um olhar didático-pedagógico operacional-reflexivo da linguagem (com base em BRITTO, 1997) e buscando a relação do sujeito com a língua sob o panorama da interlocução, da compreensão da língua em funcionamento. Conforme Geraldi (1997, p. 189), não usamos a linguagem apenas para falar e escrever sobre o mundo, nem somente sobre nossa relação com as coisas, mas,

${ }^{6}$ Como mostram estudos de Irigoite (2011, 2015), Catoia Dias (2012, 2016), Tomazoni (2012, 2016) e Pereira (2015), vinculados ao Grupo de Pesquisa 'Cultura escrita e escolarização', inserido no Núcleo de Estudos em Linguística Aplicada - NELA/UFSC. 
além disso, falamos e escrevemos sobre o modo como operamos com a linguagem. Assim, segundo o autor, nossas ações em se tratando da língua não se restringem a seu uso, mas compreendem também ações com a língua, o que significa construir sistemas de referências, interpretando os recursos expressivos para a elaboração da compreensão do mundo; ações $d a$ língua, que são os limites e as possibilidades para tornar a língua significativa e, também, ações sobre a língua, em que buscamos compartilhar sentidos para o discurso. Desse modo, a perspectiva enunciativo-discursiva, para fins de realização de análise linguística nas aulas de Língua Portuguesa, contribui com uma visão mais ampla do uso do texto.

As teorizações do Círculo de Bakhtin são de suma importância em uma elaboração didática (HALTÉ, 2008 [1998]) com vistas a analisar a linguagem, pois as concepções de língua, sujeito, texto-enunciado e gêneros nos ancoram para um trabalho que transcende a materialidade textual. As concepções bakhtinianas ajudam-nos a compreender, segundo Rodrigues (2001, 2005) e Acosta-Pereira (2008, 2012), tanto a dimensão social dos textosenunciados quanto sua dimensão verbo-visual. Em relação à primeira dimensão, Rodrigues (2001, 2005) acentua que ao analisar um texto-enunciado é imprescindível estabelecermos um olhar atento às condições de produção de determinado gênero do discurso como, por exemplo, esfera, autoria, horizonte apreciativo-ideológico e valoração; às condições de circulação, tais como esfera, interlocutor, horizonte apreciativo-ideológico do outro, meios de circulação, espaços de circulação e tempo de circulação; e também às condições de recepção, como os modos de publicação e a situação imediata de interação. Ao propor uma análise linguística à luz da perspectiva do Círculo de Bakhtin, além de estarmos atentos à dimensão social dos textosenunciados, proposta por Rodrigues $(2001,2005)$, podemos também realizá-la sob a dimensão verbo-visual, proposta por Acosta-Pereira (2008, 2012). O autor advoga em favor dessa dimensão, argumentando que há que se analisar aspectos enunciativo-discursivos, ou seja, as feições do gênero; as estratégias estilísticas e formas relativamente estáveis de acabamento, de orquestração do dizer. Além disso, na dimensão verbo-visual há também que prezar por uma análise de aspectos textuais; recursos textuais agenciados sob a baliza do gênero; aspectos linguísticos - os recursos da língua agenciados à luz das feições do gênero - e, por fim, os aspectos visuais, em que podemos analisar o modo como os elementos visuais se correlacionam com os verbais para a construção de sentidos.

A ação docente, em se tratando do ensino e da aprendizagem de Língua Portuguesa, torna-se mais efetiva na medida em que a análise linguística versa não somente sobre aspectos puramente linguísticos e metalinguísticos, mas também sobre questões sociais, culturais e ideológicas que envolvem o ato de dizer. Faraco (2009, p. 84), sobre as teorizações bakhtinianas, acentua que "o mundo interior é uma arena povoada de vozes sociais, em suas múltiplas relações de consonâncias e dissonâncias, e em permanente movimento, já que a interação socioideológica é um contínuo devir." 
Estar, portanto, ciente de questões que nos levam para além das restrições gramaticais da língua, é se abrir ao discurso e ao ato de dizer, é compreender que a língua está em diferentes esferas da atividade humana e opera de diferentes modos, instituindo relações entre diferentes sujeitos. Compreender esses fatores é um caminho para que nós e nossos alunos circulemos e, sobretudo, imirjamos nessas diversas esferas, dominando esses modos de dizer e/ou compreendendo axiologicamente por quê se diz, o que se diz, para quem se diz e onde se diz. Para Volóshinov (2014 [1929]), o locutor serve-se da língua para suas necessidades enunciativas concretas em um dado contexto concreto, não importando o aspecto da forma linguística, como sinal estável, mas enquanto signo variável e flexível.

Diante dessas considerações, e recorrendo novamente à Faraco (2009, p. 127), podemos perceber que na perspectiva enunciativo-discursiva, falar não é apenas utilizar um código num vazio, mas moldar nosso dizer às formas de um gênero no interior de uma atividade. A análise linguística, sob essa perspectiva, corrobora para que consigamos, em nossa prática docente, dar conta de questões mais sociológicas que até então nenhuma teoria linguística havia abordado de modo tão atento e efetivo.

Operar reflexivamente com a linguagem exige, pois, que tenhamos atenção especial ao texto. Portanto, embora a perspectiva enunciativo-discursiva contribua significativamente para ampliar nossa visão acerca de uma análise linguística em que o foco é a dinamicidade da produção, a interação socioverbal e o que fazemos com a linguagem no interior da atividade social, ainda assim, recorremos - para os fins de uma análise linguística operacional-reflexiva aos pressupostos da Linguística Textual sociocognitiva, à luz de Antunes (2003, 2009, 2010), de Koch (1999, 2002, 2004, 2014), de Koch e Elias (2012) e de Marcuschi (2008), por entender que a área centra-se de modo bastante consistente em questões eminentemente textuais, as quais são, de igual modo, importantes no efetivo domínio da língua.

Para a Linguística do Texto, a atenção recai justamente sobre o próprio texto, sobre os aspectos que dizem respeito a sua materialidade textual. O texto é, neste caso, unidade fundamental no trabalho de análise, de modo que a frase isolada - a parte separada do todo do texto - não contribui para um real ensino e aprendizagem da língua. Conforme Antunes (2010), a tarefa de analisar implicaria separar elementos de um determinado conjunto, no entanto, em um texto, nada é separável totalmente; tanto a frase segmentada quanto o texto segregado de seu contexto de interação, como frequentemente encontramos nos livros didáticos, não contribui para uma prática docente efetiva; fato que parece convergir com a visão da perspectiva enunciativo-discursiva da linguagem.

A partir da década de 90 até os dias atuais, a Linguística Textual passou a se preocupar não somente com o texto, mas também com o contexto interacional. Desse modo, sob o escopo epistemológico da Linguística Textual (LT) sociocognitiva, reiteramos que a compreensão de textos passou a ser entendida como "uma operação que vai além do aparato linguístico, pois se 
trata de um evento comunicativo em que se operam, simultaneamente, ações linguísticas, sociais e cognitivas" (ANTUNES, 2010, p. 31).

Assim compreendendo, importa registrar que pensar a análise linguística e, sobretudo, analisar textos à luz da LT é, de acordo com Antunes (2010, p. 49),

[...] procurar descobrir, entre outros pontos, seu esquema de composição; sua orientação temática, seu propósito comunicativo; é procurar identificar suas partes constituintes; as funções pretendidas para cada uma delas, as relações que guardam entre si e com elementos da situação, os efeitos de sentido decorrentes de escolhas lexicais e de recursos sintáticos. É procurar descobrir o conjunto de suas regularidades, daquilo que costuma ocorrer na sua produção e circulação, apesar da imensa diversidade de gêneros, propósitos, formatos, suportes em que eles podem acontecer.

Uma análise linguística operacional-reflexiva, sob esse escopo, tem, portanto, o papel de contribuir para que o professor, em sua elaboração didática (HALTÉ, 2008 [1998]), saiba operar com aspectos globais do texto, aspectos de sua construção e aspectos léxico-gramaticais. Antunes (2010, p. 16), ao argumentar em favor de um trabalho de análise de texto, salienta que o ato de analisar é importante para que seja ampliada a nossa capacidade de compreensão e entendimento do que fazemos ao processar as informações que ouvimos ou lemos. Segundo a autora, é a partir da análise de texto que desenvolvemos nossa capacidade de perceber as propriedades, as estratégias, os meios, os recursos, os efeitos, enfim, as regularidades implicadas no funcionamento da língua.

Compreender o todo de um texto, analisá-lo de acordo com as necessidades e intenções de cada momento da prática docente, faz-se necessário para que haja reflexão do processo de leitura e escrita e, sobretudo, compreensão do todo que compõe o texto. Assim, a LT, com seus estudos sobre textualidade, compreende tanto configuração linguística, em que há critérios de coesão e coerência, quanto situação comunicativa, denominados também conhecimentos de mundo, o que implica critérios de aceitabilidade, informatividade, situacionalidade, intertextualidade e intencionalidade. Cientes desses aspectos, compreendemos, a partir de Marcuschi (2008), que produzir e entender textos não é uma simples atividade de codificação e decodificação, mas um complexo processo de produção de sentido mediante atividades inferenciais. Segundo o autor, ao trabalhar com o texto, devemos tratá-lo como uma realidade e não uma virtualidade, o que faz com que nós, estudiosos da linguagem e professores de Língua Portuguesa, atentemo-nos para uma análise linguística operacional-reflexiva, e não meramente a análise gramatical em que o texto é apenas acessório ou apenas pretexto, conforme explica Geraldi (1997). 
Dessa forma, a análise linguística, sob um olhar operacional-reflexivo, busca desenvolver a capacidade comunicativa/interativa e de compreensão dos sujeitos, contribuindo para a leitura e a produção de textos nos diversos gêneros do discurso. Assim, uma análise de tal modo exige um deslocamento das funções de ensino e de aprendizagem da língua portuguesa, pois, ensinar a língua vai além de uma abordagem metalinguística, justamente porque a língua não se constitui apenas de sistema, com ela podemos interagir uns com os outros socialmente.

\section{Contribuições para a prática docente em língua portuguesa}

Pensar o ensino e a aprendizagem da língua, mais especificamente, a prática de análise linguística integrada à leitura nas aulas de Língua Portuguesa, à luz das considerações teóricometodológicas empreendidas ao longo do artigo, implica considerar que nossos leitores não virão a este texto desnudos de suas vivências com textos outros, mas são sujeitos que vão se constituindo ao longo de suas interações com o outro mediadas pela língua, pelos textosenunciados com que mantêm contato (BAKHTIN, 2011 [1952-1953]), e, por isso, irão concordar/confrontar/refutar/completar/adaptar (com) o que é dito aqui (GERALDI, 1997; $\mathrm{KOCH}$; ELIAS, 2012), enfim, produzirão sentidos na interação conosco por meio da leitura.

Como se viu, está-se propondo a articulação entre duas perspectivas sociointeracionista/enunciativo-discursiva, amparada pelos estudos bakhtinianos, e sociocognitivista/cognitivista, defendida pela Linguística Textual - cujo embasamento teórico se distingue, mas parece convergir ao lançar luz ao aspecto social/interacional dos textosenunciados os quais medeiam as relações interpessoais na sociedade.

Em se tratando das aulas de Língua Portuguesa, tendo em vista a articulação que propomos entre os dois polos teórico-epistemológicos, importa a nós, professores, - quando amparados por uma concepção dialógica de sujeito e de língua - que conheçamos quem são nossos alunos, quais são suas práticas sociais de uso da língua e, então, empreendamos uma ação pedagógica amparada por uma elaboração didática (HALTÉ, 2008 [1998]) que faculte a eles vivenciar leituras de textos-enunciados em gêneros do discurso diversos (BAKHTIN, 2011 [195253]), de modo a ampliar suas experiências com a língua e também seu conhecimento sobre a língua, da língua e com a língua (GERALDI, 1997).

Analisar textos se refere ao conhecimento sobre a língua; o que pode servir para outros propósitos como: "o domínio de certos recursos expressivos que não fazem parte daqueles já usados pelos alunos" (GERALDI, 1997, p. 192). Isso a fim de que possam se tornar leitores proficientes - consequentemente, também produtores de textos-enunciados, uma vez que, como defende Geraldi (1997), o trabalho com a leitura e a produção textual está imbricado em boa medida, estando a análise linguística no interior de e a partir dessas práticas. 
Acerca do que se discutiu entre o que significa uma análise gramatical da língua - tendo por base a gramática tradicional - e uma análise linguística na escola, percebe-se que não é objetivo das aulas de Língua Portuguesa tornar o aluno um analista da língua, mas, leitor e produtor de textos-enunciados situados cultural e historicamente nessa língua, de modo proficiente. Para isso, o trabalho com os gêneros do discurso, na articulação dos usos primários aos usos secundários, precisa orientar a prática docente, a fim de que as especificidades das diferentes configurações textuais - como condições de produção e recepção do texto, espaço social em que circula, auditório social e itens afins (BAKHTIN, 2011 [1952-1953]) - sejam abordadas, contribuindo para que o aluno, quando em contato com esses gêneros para além da sala de aula, possa compreender os sentidos do texto-enunciado, agenciando para este fim conhecimentos cognitivos e discursivos. Tendo isso em vista, a ação docente precisa se atentar para a seleção dos textos em gêneros a serem trabalhados em sala de aula, prezando por aqueles que, como textos-enunciados concretos, de circulação social, tanto primários como secundários, ampliem o que o aluno tem a dizer, o que contribuirá também para a ampliação de suas estratégias de dizer e de sua capacidade de compreender outros projetos de dizer (GERALDI, 1997).

Com base em Koch e Elias (2012) e em Geraldi (1997), o leitor trabalha para produzir os sentidos do que lê, observando as "pistas" textuais do autor, explícitas e implícitas, assim como agenciando seus próprios conhecimentos. Desse modo, para que o aluno, em sua condição de leitor, concorde ou não com as ideias do autor, complete-as, refute-as, adapte-as, enfim, para que produza sentidos ao que lê, é necessário que tenha se apropriado de estratégias de leitura que o permitam fazê-lo, mobilizando, como vimos, seus conhecimentos linguísticos, enciclopédicos e interacionais (ANTUNES, 2009; KOCH; ELIAS, 2012), além de outras ações sociocognitivas como a decodificação, a localização de informação, a inferenciação, a ativação de esquemas cognitivos (LEFFA, 1996). Sendo assim, para que isso aconteça, precisamos contemplar em nossa prática docente atividades de leitura de textos-enunciados - apresentados em seu suporte e não de maneira fragmentada, visto que para uma exitosa compreensão textual é necessário um texto coeso e coerente, não constituído de frases soltas e ideias isoladas, mas de um "tramado"7 muito bem desenvolvido e articulado à situação de interação que incitem a mobilização desses conhecimentos pelos alunos.

Tendo isso em vista, com o objetivo de que nosso aluno consiga produzir sentidos àquilo que lê de maneira proficiente, precisamos articular ações didático-pedagógicas que tomem textos-enunciados como unidade de ensino, chamando a atenção dos estudantes aos aspectos textuais e interacionais implicados na interação entre autor e leitor. Para isso, precisamos

\footnotetext{
${ }^{7}$ Aqui fazemos alusão à metáfora da tessitura de Geraldi (1997), utilizada também, a nosso ver, por Antunes (2010) ao se referir à produção textual. A leitura e a produção de textos seriam como um tecido resultante do entrelaçamento dos fios trazidos pelo autor e pelo leitor para a produção dos sentidos.
} 
desenvolver atividades de compreensão leitora - e não mais atividades de encontrar respostas para um texto, como se configura(va)m as atividades de interpretação textual - que envolvam os alunos em estratégias complexas de compreender o texto, de tentar alcançar seus sentidos e suas intenções por meio da apropriação dessas mesmas estratégias (ANTUNES, 2010). Desse modo, compreendendo que o ato de decodificar o texto e de localizar informações são atividades cognitivas fundamentais demandadas pela leitura, é necessário que nos empenhemos em garantir que nossos alunos sejam capazes de realizá-las a fim de que possam acessar atividades cognitivas mais complexas implicadas no processamento do ato de ler textosenunciados. O leitor, para poder compreender, refletir e avaliar um texto, tem de mapear as informações contidas nele e estabelecer relações com os seus conhecimentos linguístico, enciclopédico e interacional, fundamentais na produção dos sentidos (CATOIA DIAS, 2012).

Vê-se que, no trabalho de análise de textos-enunciados integrada à leitura, saber decodificar o texto e localizar informações - atividades comuns principalmente ao processo de alfabetização - são algumas das condições para uma compreensão efetiva do que se lê. É necessário, além disso, que o aluno tenha vivências com a escrita que lhe permitam transitar por diferentes leituras, não sendo a leitura entendida aqui como a simples decodificação do código linguístico. Sendo assim, o aluno será capaz de realizar outras ações como inferir os implícitos do texto, relacioná-lo ao seu conhecimento prévio, perceber suas intertextualidades, recuperar referentes, observar o modo e as estratégias que o autor escolhe para dizer o que quer dizer, enfim, negociará sentidos com o autor do texto na situação real de interação de leitura.

Com o intuito de dar concretude ao que vimos tratando, e por entendermos convergir com nossa discussão, retomamos a proposta metodológica de Acosta-Pereira (2008, 2012, 2014) e Rodrigues (2001, 2005), os quais propõem um 'caminho de questionamentos' para a análise de textos-enunciados. Tal caminho vem a orientar o trabalho de análise da língua, contemplando seus aspectos sociais e verbo-visuais, conforme mostram os gráficos extraídos de Acosta-Pereira (2014):

Quadro 1 - Dimensões de análise dos textos-enunciados
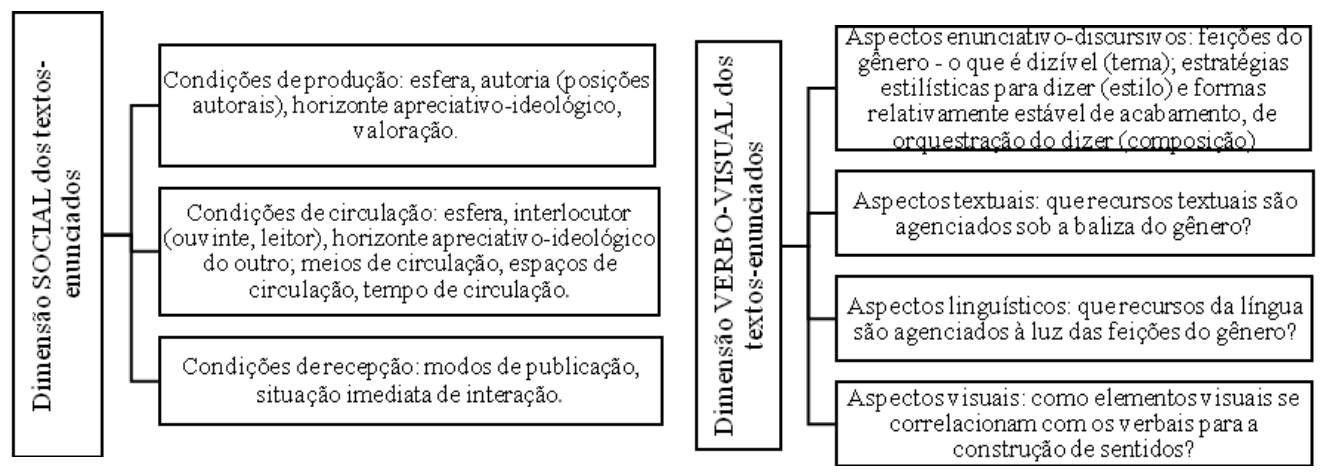

Fonte: Acosta-Pereira (2014, p. 13) 
Trata-se de uma proposta que, em nosso entendimento, destaca aspectos para o trabalho de análise linguística que contemplam tanto a dimensão sociocultural quanto sociocognitiva, como se discutiu neste artigo. O professor, tomando por base tal sugestão de análise, poderá desenvolver atividades em sala de aula que envolvam desde as conjecturas histórico-culturais e ideológico-valorativas de constituição e funcionamento dos textosenunciados - como a situação de interação, a esfera de produção, circulação e recepção, a autoria, o papel do leitor na construção do texto-enunciado, a dimensão temporal-espacial - até seus aspectos de ordem temática, de estilo e de composição - como os recursos linguísticos, textuais e lexicais e elementos visuais na relação com elementos verbais agenciados na produção e na leitura do texto-enunciado (ACOSTA-PEREIRA, 2014). O docente pode abordar o texto-enunciado escolhido para o trabalho de análise por meio de questões que levem o aluno a refletir sobre aquele uso específico da linguagem e a reconhecer e compreender como diferentes recursos da língua são agenciados na produção dos sentidos (ACOSTA-PEREIRA, 2011, 2013). Sob a ótica da dimensão social, o professor poderá indagar, por exemplo, qual o suporte de circulação do texto, quando e onde é publicado, a quem se destina; e acerca da dimensão verbo-visual, poderá perguntar a respeito do que trata o texto, que relação mantém com textos outros, como agencia e por que agencia determinados recursos gramaticais, lexicais, discursivos e/ou visuais. Enfim, assumindo tal postura teórica, no propósito de fazer nosso aluno operar e refletir sobre a língua, podemos planejar e articular nossas intervenções em sala de aula sem ter de seguir modelizações a priori. Importa, pois, que sejamos protagonistas de nossa ação docente e nos esforcemos em exercer um efetivo e teoricamente amparado ensino de língua (RODRIGUES; CERUTTI-RIZZATTI, 2011).

Sendo assim, concebemos que empreender ações didático-pedagógicas ancoradas no diálogo teórico-epistemológico e metodológico proposto neste artigo é, de algum modo, alçar voo em direção a um ensino de Língua Portuguesa mais efetivo em relação ao uso e à reflexão da língua, o que parece ser relevante aos nossos alunos, como sujeitos constituídos e constituidores dessa língua. Dessa maneira, reenunciamos Marcuschi (2008, p. 229-230) que, em interlocução com a concepção de análise linguística e de leitura que levantamos no diálogo entre as diferentes perspectivas teóricas abarcadas neste artigo, arremata o que seria a ação de compreender um texto: "compreender exige habilidade, interação e trabalho. [...] Compreender não é uma ação apenas linguística ou cognitiva. É muito mais uma forma de inserção no mundo e um modo de agir sobre o mundo na relação com o outro dentro de uma cultura e uma sociedade". Dessa forma, ensinar análise linguística de maneira articulada à leitura - e também à produção de textos - não constitui uma ação desvinculada do meio em que se vive, mas, diz respeito à inserção de nossos alunos em diferentes espaços sociais, sem restrições. Isso, em nossa compreensão, com base em Cerutti-Rizzatti, Daga e Catoia Dias (2014), seria nosso grande desiderato como professores de Língua Portuguesa. 


\section{Considerações finais}

Procuramos, por meio de um diálogo entre os escritos do Círculo de Bakhtin e os da Linguística Textual, compreender a prática da análise linguística em favor do ensino e da aprendizagem da leitura de textos, em uma tentativa de delinear possibilidades outras ao trabalho docente em linguagem com vistas a uma formação humana mais ampla e integral. Nesse sentido, entendemos necessária a implementação, nas escolas de Educação Básica, de uma prática de análise linguística que, na convergência de uma dimensão sociologista a uma dimensão cognitivista, seja mediada pelos gêneros do discurso e pautada numa concepção de língua como prática social, não a tomando simplesmente como sistema abstrato, mas como lócus da interação em que as relações interpessoais se estabelecem.

Assim compreendendo, estamos cientes de que a análise linguística que deve ser eliciada nos espaços escolares não é desvinculada do meio, das relações interpessoais, da interação social, enfim, do mundo da vida (BAKHTIN, 2010 [1920-24]), assim como não se dissocia do âmbito teórico, abstrato, do mundo da cultura. Como prática articulada à leitura e à produção textual, portanto experienciada cotidianamente, ela deve contribuir para o desenvolvimento humano tanto no que tange à ampliação das estratégias de ler e de dizer de nossos alunos - especificidade da educação em linguagem - quanto, de modo mais amplo, à apropriação das produções culturais historicamente acumuladas pelo gênero humano com vistas à inserção e participação crítica dos discentes em diferentes esferas da atividade humana, tendo em vista suas próprias experiências, vivências, sentimentos e valorações. Isso porque compreender a língua é usá-la para diferentes propósitos interacionais, em diversos espaços sociais; é, pois, agir sobre o mundo e ser, ao mesmo tempo, por ele modificado.

Ao fim, registramos estarmos cientes, também, de que este texto não é e não pode ser estanque em si mesmo; é tão somente um elo, nessa cadeia discursiva, que responde a estudos anteriores e aponta para outros novos estudos relativos à prática de análise linguística e suas implicações para o ensino e a aprendizagem de língua portuguesa, de modo a se produzirem, na esfera acadêmica, novas inteligibilidades e possibilidades de encaminhamentos outros que atendam às urgentes demandas escolares vivenciadas por nós, professores.

\section{Referências}

ACOSTA-PEREIRA, Rodrigo. O gênero jornalístico notícia: dialogismo e valoração. 2008. Dissertação (Mestrado em Linguística) - Programa de Pós-Graduação em Linguística, Universidade Federal de Santa Catarina, Florianópolis, 2008. 
ACOSTA-PEREIRA, Rodrigo. Contribuições dos estudos sobre gêneros do discurso para a análise linguística em sala de aula: perspectivas dialógicas. Revista Caminhos em Linguística Aplicada, v. 5, n. 2, p. 01-41, 2011.

ACOSTA-PEREIRA, Rodrigo. 0 gênero carta de conselhos em revistas online: na fronteira entre 0 entretenimento e a autoajuda. 2012. Tese (Doutorado em Linguística) - Programa de PósGraduação em Linguística, Universidade Federal de Santa Catarina, Florianópolis, 2012.

ACOSTA-PEREIRA, Rodrigo. A prática de análise linguística mediada pelos gêneros do discurso: matizes sócio-históricos. Revista Letrônica, v. 06, n. 2, p. 494-520, 2013.

ACOSTA-PEREIRA, Rodrigo. A análise de textos-enunciados como atividade precedente à elaboração didática. Revista Intersecções (Jundiaí), v. 07, n. 3, p. 04-23, 2014.

ANTUNES, Irandé. Aula de Português: encontro \& interação. São Paulo: Parábola Editorial, 2003, p. 85-153.

ANTUNES, Irandé. Língua, texto e ensino: outra escola possível. São Paulo: Parábola Editorial, 2009.

ANTUNES, Irandé. Análise de textos: fundamentos e práticas. São Paulo: Parábola, 2010.

BAKHTIN, Mikhail. Para uma filosofia do ato responsável [tradução Valdemir Miotello \& Carlos Alberto Faraco]. São Carlos: Pedro \& João Editores, 2010 [1920-1924].

BAKHTIN, Mikhail. Os gêneros do discurso. In: BAKHTIN, Mikhail. Estética da criação verbal [tradução Paulo Bezerra]. 4. ed. São Paulo: Martins Fontes, 2011 [1952-1953], p. 261-306.

BAKHTIN, Mikhail. Estética da Criação Verbal. Tradução de Paulo Bezerra. 5. ed. São Paulo: Martins Fontes, 2011 [1979].

BRASIL. SEF. Parâmetros curriculares nacionais: terceiro e quarto ciclos do ensino fundamental: língua portuguesa. Brasília: MEC/SEF, 1998.

BRITTO, Luiz Percival Leme. A sombra do caos: ensino de língua x tradição gramatical. Campinas/SP: Mercado de Letras, 1997.

BRITTO, Luiz Percival Leme. Contra o consenso. Campinas/SP: Mercados das Letras, 2003.

BRITTO, Luiz Percival Leme. Letramento e alfabetização: implicações para a educação infantil. In: FARIA, Ana Lúcia Goulart de; MELLO, Suely Amaral. (Org.) O mundo da escrita no universo da pequena infância. São Paulo: Autores Associados, 2005. p. 5-21.

BRITTO, Luiz Percival Leme. Inquietudes e desacordos: a leitura além do óbvio. Campinas/SP: Mercado das Letras, 2012.

CATOIA DIAS, Sabatha. $\mathbf{O}$ ato de ler e a sala de aula: concepções docentes acerca do processo de ensino e de aprendizagem de leitura/práticas de leitura. 2012. Dissertação (Mestrado em Linguística) - Programa de Pós-Graduação em Linguística, Universidade Federal de Santa Catarina, Florianópolis, 2012. https://doi.org/10.17771/PUCRio.PDPe.20886 
CATOIA DIAS, Sabatha. Entre ecos e travessias: um olhar para o ato de ler no processo de educação em linguagem na esfera escolar. 2016. Tese (Doutorado em Linguística) - Programa de Pós-Graduação em Linguística, Universidade Federal de Santa Catarina, Florianópolis, 2016.

CERUTTI-RIZZATTI, Mary Elizabeth. Uma discussão sobre implicações das fronteiras do conceito de letramento. Florianópolis, 2011 (mimeo.). https://doi.org/10.1590/S010173302012000100018

CERUTTI-RIZZATTI, Mary Elizabeth; DAGA, Aline Cassol; CATOIA DIAS, Sabatha. Intersubjetividade e intrassubjetividade no ato de ler: a formação de leitores na Educação Básica. Calidoscópio, v. 12, n. 2, p. 226-238, 2014. https://doi.org/10.4013/cld.2014.122.10

FARACO, Carlos Alberto. Linguagem e diálogo: as ideias linguísticas do Círculo de Bakhtin. São Paulo: Parábola Editorial, 2009.

FISCHER, Steven Roger. História da leitura. São Paulo: UNESP, 2006.

GEE, James Paul. A strange fact about not learning to read. In: J.P. GEE, Situated language and learning: a critique of traditional schooling. London, Routledge, 2004.

GERALDI, João Wanderley. O texto na sala de aula. 3. ed. Cascavel: ASSOESTE, 1984. https://doi.org/10.17851/2447-0554.3.3.57-59

GERALDI, João Wanderley. Portos de passagem. 4. ed. São Paulo: Martins Fontes, 1997.

GERALDI, João Wanderley. Ancoragens: estudos bakhtinianos. São Carlos: Pedro \& João Editores, 2010.

HALTÉ, Jean François. O espaço didático e a transposição (L'espace didactique et la transposition). Pratiques. Metz: Siège Social, n. 97-98, p. 171-192, juin 1998. Fórum Linguístico, Florianópolis, v. $\quad 5, \quad$ n. $\quad 2, \quad$ p.117-139, jul./dez. $2008 \quad$ [1998]. https://doi.org/10.3406/prati.1998.2485

IRIGOITE, Josa Coelho da Silva. Vivências escolares em aulas de português que não acontecem: a (não) formação do aluno leitor e produtor de textos-enunciado. 2011. Dissertação (Mestrado em Linguística) - Programa de Pós-graduação em Linguística, Universidade Federal de Santa Catarina, Florianópolis, 2011.

IRIGOITE, Josa Coelho da Silva. Aula de Português como encontro entre a outra palavra e a palavra outra: um estudo sobre a ecologia da apropriação da escrita na esfera escolar. 2015. Tese (Doutorado em Linguística) - Programa de Pós-graduação em Linguística, Universidade Federal de Santa Catarina, Florianópolis, 2015.

$\mathrm{KOCH}$, Ingedore Grunfeld Villaça. O desenvolvimento da Linguística Textual no Brasil. D.E.L.T.A, v.15, n. especial, p. 165-180, 1999. https://doi.org/10.1590/S0102-44501999000300007

KOCH, Ingedore Grunfeld Villaça. Desvendando os segredos do texto. São Paulo: Cortez, 2002.

$\mathrm{KOCH}$, Ingedore Grunfeld Villaça. Introdução à Linguística Textual. São Paulo: Martins Fontes, 2004.

$\mathrm{KOCH}$, Ingedore Grunfeld Villaça. $\mathrm{O}$ texto e a construção dos sentidos. São Paulo: Contexto, 2014. 
$\mathrm{KOCH}$, Ingedore Grunfeld Villaça; ELIAS, Vanda Maria. Ler e compreender os sentidos do texto. São Paulo: Contexto, 2012.

LEFFA, Vilson. O conceito de leitura. In: LEFFA, Vilson. Aspectos da leitura. Porto Alegre: Sagra, 1996, p. 9-44.

MARCUSCHI, Luiz Antônio. Produção textual, análise de gêneros e compreensão. São Paulo: Parábola, 2008.

MEDVIÉDEV, Pavel Nikolaievitch. O método formal nos estudos literários: introdução crítica a uma poética sociológica. Tradução de Ekaterina Américo e Sheila Grillo. São Paulo: Contexto, 2012 [1928]. p. 193-207.

PEREIRA, Hellen Melo. O lugar das práticas de letramento na esfera escolar: um estudo sobre o encontro aula de Língua Portuguesa. 2015. Dissertação (Mestrado em Linguística) Universidade Federal de Santa Catarina, Florianópolis, 2015.

RODRIGUES, Rosângela Hammes. A constituição e o funcionamento do gênero jornalístico artigo: cronotopo e dialogismo. 2001. 356f. Tese (Doutorado em Linguística Aplicada) Pontifícia Universidade Católica de São Paulo, São Paulo, 2001.

RODRIGUES, Rosângela Hammes. Os gêneros do discurso na perspectiva dialógica da linguagem: a abordagem do Círculo de Bakhtin. In: MEURER, José Luiz; BONINI, Adair; MOTTA-ROTH, Désirée (org.). Gêneros: teorias, métodos, debates. São Paulo, Parábola, 2005. p. 152-183.

RODRIGUES, Rosângela Hammes; CERUTTI-RIZZATTI, Mary Elizabeth. Linguística Aplicada: ensino de língua materna. Florianópolis: LLV/CCE/UFSC, 2011.

TOMAZONI, Eloara. Produção textual escrita e escola: um olhar sobre ancoragens de concepções docentes. 2012. Dissertação (Mestrado em Linguística) - Programa de Pósgraduação em Linguística, Universidade Federal de Santa Catarina, Florianópolis, 2012.

TOMAZONI, Eloara. $\mathbf{O}$ ato de escrever em encontros na escola. 2016. Tese (Doutorado em Linguística) - Programa de Pós-graduação em Linguística, Universidade Federal de Santa Catarina, Florianópolis, 2016.

VOLOCHÍNOV, Valentin Nikolaevich. A construção da enunciação e outros ensaios. Organização, tradução e notas de João W. Geraldi. São Carlos/SP: Pedro \& João Editores, 2013 [1930].

VOLÓSHINOV, Valentín Nikoláievich. El Marxismo y la filosofia del lenguage. Buenos Aires: Ediciones Godot, 2014 [1929].

Recebido em: 20/05/2018

Aceito em: 06/11/2019 